Macedonian Pharmaceutical Bulletin, 66 (Suppl 1) 127 - 128 (2020)

Online ISSN 1857 - 8969

UDC: $615.453 .6 .015 .153: 615.212$

DOI: 10.33320/maced.pharm.bull.2020.66.03.063

Short communication

\title{
Formulation development of prolonged-release matrix tablets - factors influencing drug dissolution rate
}

\author{
Oja Ali Memed ${ }^{1} *$, Maja Hadzieva-Gigovska ${ }^{1}$, Dejan Kuneski ${ }^{1}$, Eleonora Trajanovska ${ }^{1}$, \\ Packa Antovska ${ }^{1}$, Sonja Ugarkovic ${ }^{1}$, Maja Simonoska Crcarevska ${ }^{2}$, \\ Marija Glavas Dodov ${ }^{2}$
}

${ }^{1}$ Research \& Development, Alkaloid AD-Skopje, Blvd. Aleksandar Makedonski 12, 1000 Skopje, N. Macedonia

${ }^{2}$ Faculty of Pharmacy, Ss. Cyril and Methodius University, Majka Tereza 47, 1000 Skopje, N. Macedonia

\section{Introduction}

Chronic pain remains a major societal burden that is associated with a decline of normal daily functioning and quality of life. Appropriate management of chronic pain aims to improve quality of life and daily function by alleviating not only pain symptoms, but also comorbid conditions (Martin et al., 2016). Oral opioids have become the drugs of choice for the treatment of moderate-to-severe chronic pain because of flexibility, convenience and ability to maintain relatively steady blood concentrations (Petrovska Jovanovska et al., 2018). Controlled release formulations could be a suitable dosage forms in chronic pain management (i.e. reduced dose frequency, less fluctuation in plasma concentration, reduced side effects and good patients' compliance).

For the design of generic oral drug product with prolonged release properties using Quality by Design, $Q b D$ approach, a variety of polymers with different physicochemical characteristics could be used in order to modulate the drug release behaviors. Therefore, during the one facor-at time experiments it is highly desirable to determine the critical material attributes (CMAs) of the selected excipients (controlled release polymer/s), to evaluate the transport mechanism involved in the drug release process, as well as to be able to predict quantitatively the resulting drug release kinetics as the product most important critical quality attributes (CQA) (Saurí et al., 2014).

The aim of this study was to develop a generic film-coated matrix tablets with water soluble opioid drug $(A P I)$. In that direction, we have evaluated the influence of different types of polymers (HPMC, $P V a c / P V P, H E C, P E O$ and PMAMMMA) on the properties of designed tablets in order to find the polymer or combination of polymers which will give most similar release profile with the reference drug product.

\section{Materials and methods}

Different formulations of film-coated tablets were prepared by wet granulation process using $S 1$. HPMC (Colorcon, DE), S2. HEC (Ashland, UK), S3. $P V A c / P V P$ (BTC, DE), S4. PEO (Colorcon, DE) and S5. PMAMMMA (Eudragit, DE) as drug release modifying polymers in concentration of $30 \%(w / w)$ respectively. The active substance (API, opioid analgesic, hydrochloride salt, BCS class II) was preblended with microcrystalline cellulose (FMC, IR) and selected polymer (S1-5) in high shear granulator

\footnotetext{
*omemed@alkaloid.com.mk
} 
(Diosna, DE). Afterwards, granulation liquid was added, the wet mass was passed through $0.630 \mathrm{~mm}$ sieve and the granules were subsequently oven dried (MOV-212S; Panasonic, JP). The dried granules where passed through $0.813 \mathrm{~mm}$ sieve and blended with magnesium stearate (FaciSpa Carasco, IT). The final blends were subsequently compacted into round $7.0 \mathrm{~mm}$ tablets with compression force of 5.0$5.5 \mathrm{kN}$ (Korsch XL 100, DE). Prepared tablet cores were coated with Opadry 20A220058 Yellow (Colorcon, DE), (O'HARA Labcoat M).

Final blends were characterized for bulk/tapped density, Carr-index, Hausner ratio and angle of repose according to Ph. Eur. 8.7 methods. Prepared film-coated tables were evaluated for mass and mass variation, hardness, thickness and diameter (TBH $425 \mathrm{TD}$, Erweka GmBh, DE). In vitro drug release studies were performed for $12 \mathrm{~h}$ in $900 \mathrm{~mL}$ simulated gastric fluid ( $\mathrm{Ph}$. Eur) as dissolution media maintained at $37 \pm 0.5{ }^{\circ} \mathrm{C}$. Obtained dissolution profiles were compared with the reference drug product, according to the EMA guideline for bioequivalence (EMEA, 2010). To analyze the in vitro release data various kinetic models were used to describe the release kinetics.

\section{Results and discussion}

The Quality target product profile (QTPP) was set according to reference drug characteristics (round biconvex film-coated tablets with mass of 135.00 $\mathrm{mg} \pm 7.5 \%$, hardness $11-13 \mathrm{kP}$, diameter 7.00 $\mathrm{mm} \pm 0.15$ and thickness 3.1-3.6 $\mathrm{mm}$ ) and appropriately justified in all segments. The final blends characterization showed differences in the flow properties of the granules, namely $S 1$ and $S 2$ had a fair flow, whiles $S 3-5$ had acceptable flow properties. All manufactured blends, regardless their flow, were appropriately compressed and filmcoated. Prepared film-coated tablets were smooth and elegant in appearance. The formulated tablets passed the uniformity of weight, uniformity of thickness and diameter tests respectively and were in acceptance criteria according to QTPP of the reference product, except for $S 3$, were results for hardness of the tablets was in unsatisfactory level $(2.3 \mathrm{kP})$. Obtained results from the in vitro release studies pointed the influence of the used polymers on API release behavior. The $S 4$ and $S 5$ showed significant differences with respect to the release rate of API compared to reference product (similarity factor $f_{2}$ of 34.64 and 14.93 , respectively). On the other side, $S 1-3$ had the $f 2$ of 53.5, 51.1 and 55.2, respectively, thus representing potential candidates for further formulation modification and evaluation. The drug release data from all examined samples fit well to the Higuchi expressions, which points that drug release mechanism independently from which polymer/polymers will be used, will be a complex mixture of diffusion, swelling and erosion.

\section{Conclusion}

Prolonged release film-coated tablets of watersoluble opioid analgesic have been successfully formulated using HPMC, HEC or PVAc/PVP as drug release modifiers. The type of polymer used as CMA was found to significantly affect the tablet properties, especially the API release rate, as the CQA of the final drug product and were able to provide the desired drug release over a $12 \mathrm{~h}$ time period.

\section{References}

EMEA, 2010. Guideline on the investigation of bioequivalence. pp. 1-27. Available at: https://doi.org/CPMP/EWP/QWP/1401/98.

Martin, C., De Baerdemaeker, A., Poelaert, J., Madder, A., Hoogenboom, R., Ballet, S., 2016. Controlledrelease of opioids for improved pain management. Materials Today 19(9), 491-502.

Petrovska Jovanovska, V., Pejov, Lj., Petrovska, A., Ugarkovic, S., Galeva, M., Simonoska Crcarevska, M., Glavas Dodov, M., 2018. Physicochemical characterisation and in vitro evaluation of modified release matrix tablets: The role of different grades of hydroxypropylmethyl cellulose. Mac. Pharm. Bull. 63(2), in press.

Saurí, J., Millán, D., Suñé-Negre, J., Colom, H., Ticó, J., Miñarro, M., Pérez-Lozano, P., García-Montoya, E., 2014. Quality by Design approach to understand the physicochemical phenomena involved in controlled release of captopril SR matrix tablets. Int. J. Pharm. 477(1-2), 431-441.

Maced. Pharm. Bull. 66 (Suppl 1) 127 - 128 (2020) 